Neuropharmacology and analgesia

\title{
Pharmacodynamics of potassium channel openers in cultured neuronal networks
}

\author{
Calvin Wu $\mathrm{Wu}^{\mathrm{a}, \mathrm{b}, \mathrm{c}, *}$, Kamakshi V. Gopal ${ }^{\mathrm{a}, \mathrm{c}}$, Thomas J. Lukas ${ }^{\mathrm{d}}$, \\ Guenter W. Gross ${ }^{\mathrm{b}, \mathrm{c}}$, Ernest J. Moore ${ }^{\mathrm{a}, \mathrm{c}, \mathrm{d}}$ \\ a Department of Speech and Hearing Sciences, University of North Texas, Denton, TX 76203, United States \\ ${ }^{\mathrm{b}}$ Department of Biological Sciences, University of North Texas, Denton, TX 76203, United States \\ ${ }^{\text {c } C e n t e r ~ f o r ~ N e t w o r k ~ N e u r o s c i e n c e, ~ U n i v e r s i t y ~ o f ~ N o r t h ~ T e x a s, ~ D e n t o n, ~ T X ~ 76203, ~ U n i t e d ~ S t a t e s ~}$ \\ ${ }^{\mathrm{d}}$ Department of Molecular Pharmacology and Biological Chemistry, Feinberg School of Medicine, Northwestern University, Chicago, IL 60611, United States
}

\section{A R T I C L E I N F O}

\section{Article history:}

Received 14 January 2014

Received in revised form

6 March 2014

Accepted 17 March 2014

Available online 25 March 2014

Keywords:

Microelectrode array

Spontaneous activity

Multichannel extracellular recording

Pentylenetetrazol

Tinnitus

\begin{abstract}
A B S T R A C T
A novel class of drugs - potassium $\left(\mathrm{K}^{+}\right)$channel openers or activators - has recently been shown to cause anticonvulsive and neuroprotective effects by activating hyperpolarizing $\mathrm{K}^{+}$currents, and therefore, may show efficacy for treating tinnitus. This study presents measurements of the modulatory effects of four $\mathrm{K}^{+}$ channel openers on the spontaneous activity and action potential waveforms of neuronal networks. The networks were derived from mouse embryonic auditory cortices and grown on microelectrode arrays. Pentylenetetrazol was used to create hyperactivity states in the neuronal networks as a first approximation for mimicking tinnitus or tinnitus-like activity. We then compared the pharmacodynamics of the four channel activators, retigabine and flupirtine (voltage-gated $\mathrm{K}^{+}$channel $\mathrm{K}_{\mathrm{V}} 7$ activators), NS1619 and isopimaric acid ("big potassium" BK channel activators). The EC $_{50}$ of retigabine, flupirtine, NS1619, and isopimaric acid were $8.0,4.0,5.8$, and $7.8 \mu \mathrm{M}$, respectively. The reduction of hyperactivity compared to the reference activity was significant. The present results highlight the notion of re-purposing the $\mathrm{K}^{+}$channel activators for reducing hyperactivity of spontaneously active auditory networks, serving as a platform for these drugs to show efficacy toward target identification, prevention, as well as treatment of tinnitus.
\end{abstract}

(c) 2014 Elsevier B.V. All rights reserved.

\section{Introduction}

As primary regulators of neuronal excitability, potassium $\left(\mathrm{K}^{+}\right)$ channels have been a major research focus in drug discovery and development. Within this diverse and ubiquitous membrane protein, the $\mathrm{KCNQ} / \mathrm{K}_{\mathrm{V}} 7$ family of voltage-gated $\mathrm{K}^{+}$channels have gained increased attention for its role in neuropathic pain, epilepsy, cardiac arrhythmia, hearing loss, and tinnitus, and are considered promising drug targets (Jentsch, 2000; Li et al., 2013; Wulff et al., 2009). A novel anti-epileptic drug approved by the Food and Drug Administration in 2011 - retigabine - targets the KCNQ channel by activating a hyperpolarizing $\mathrm{K}^{+}$current, thereby, reducing excitability and attenuating seizure hyperactivity (Gunthorpe et al., 2012; Large et al., 2012). As a result, other $\mathrm{K}^{+}$ channel openers were discovered during the interim period. Flupirtine, a structural analog of retigabine, and originally marketed as an analgesic, was found to exert a similar mode of action

\footnotetext{
* Corresponding author at: Department of Speech and Hearing Sciences, University of North Texas 1155 Union Circle \# 305010, Denton, Texas 76203-5017, United States.

E-mail address: calvinwu@my.unt.edu (C. Wu).
}

on the neuronal KCNQ channel (Devulder, 2010). In addition to the antiepileptic promise, retigabine and flupirtine both exhibit neuroprotective properties against cell death induced by serum withdrawal (Boscia et al., 2006), and cisplatin-induced peripheral neuropathy (Nodera et al., 2011).

An additional type of $\mathrm{K}^{+}$channel - the calcium-activated large conductance $\mathrm{K}^{+}$channel, or $\mathrm{BK} / \mathrm{K}_{\mathrm{Ca}} 1.1$ - was also a major target for extending the therapeutic promises of $\mathrm{K}^{+}$channel openers (see N'Gouemo, 2011). The BK channel regulates fast after hyperpolarization of the action potential and serves as a feedback control of intracellular calcium (Jaffe et al., 2011). Through such a neuronal mechanism, the BK channel opener NS1619 was found to attenuate neuronal hyperactivity in the 4-aminopyridine model of seizure (Zhang et al., 2003), as well as reduce neuropathic pain in rats with peripheral nerve injury (Chen et al., 2009).

In this study, we tested retigabine, flupirtine, NS1619, and isopimaric acid on central nervous system networks derived from the auditory cortex region of embryonic mice. Isopimaric acid is a novel natural product with pharmacological activity as a BK channel opener (Imaizumi et al., 2002), although not presently in therapeutic use. Using microelectrode array recordings of network spontaneous activity, we present quantitative measurements 
of the pharmacological responses, and compare the pharmacodynamics of each drug from the class of KCNQ channel openers and the BK channel openers. In addition, we induced hyperactivity with pentylenetetrazol to model the possible dynamics of tinnitus (Wu et al., 2011) - an auditory disorder highly suspected to be of cortical origin (Eggermont, 2008; Roberts et al., 2010), but lower brainstem structures may not be exempt (Kaltenbach, 2007; Manzoor et al., 2012). As the therapeutic values of the four $\mathrm{K}^{+}$ channel openers on the auditory cortical tinnitus-like activity were observed and evaluated, it was concluded that the results from this study may serve as the basis for possible re-purposing of these compounds for the treatment of tinnitus.

\section{Materials and methods}

\subsection{Microelectrode array fabrication}

Fabrication and preparation of microelectrode arrays, as well as detailed recording techniques have been described previously (Gross et al., 1985). Indium-tin oxide sputtered glass plates were photoetched, spin-insulated with methyltrimethoxysilane, cured, deinsulated at the electrode tips with laser shots and electrolytically gold-plated to reduce the interface impedance to $1.0 \mathrm{M} \Omega$ at $1.0 \mathrm{kHz}$. A hydrophilic adhesion island for cell growth in the center of the 64-electrode matrix was generated by butane flaming to approximately $3.0 \mathrm{~mm}$ in diameter. The surfaces were treated with poly-D-lysine and laminin prior to cell culture.

\subsection{Neuronal cell culture}

The care and use of animals in this study were approved by and performed in accordance with the guidelines of the Institutional Animal Care and Use Committee of the University of North Texas. Cell culture techniques have been previously described for auditory cortical tissues (Gopal and Gross, 1996). Mouse embryos (Balb-C/ICR, embryonic age E17) were extracted from the dame after $\mathrm{CO}_{2}$ narcosis and cervical dislocation. Tissue from the auditory cortex regions was dissected - for growing networks enriched in auditory cortical neurons - minced, digested with papain before trituration in Dulbecco's Modified Minimal Essential Medium (DMEM), with $4 \%$ fetal bovine serum and $4 \%$ horse serum. The cell suspension was seeded on the microelectrode array at $700 \mathrm{~K} / \mathrm{ml}$ with all cell types present in the parent tissue at the time of isolation. Cultures were transitioned to $6 \%$ horse serum medium after $24 \mathrm{~h}$ and maintained biweekly by half medium changes (osmolarity: $300-320 \mathrm{mOsm} / \mathrm{kg}$ ), under constant $10 \% \mathrm{CO}_{2}$ and $90 \%$ air, at $37^{\circ} \mathrm{C}$. Cultures $26 \pm 2$ days in vitro were used for recordings $(n=66)$.

\subsection{Electrophysiological recordings}

Microelectrode arrays were assembled into sterile recording chambers consisting of stainless steel chamber blocks mounted on a heated base plate attached to an inverted microscope stage. Temperature was maintained at $37 \pm 0.2^{\circ} \mathrm{C}$ by a custom thermocouple controlled power supply, providing direct current to power resistors on the base plate. All experiments were performed under DMEM stock medium without serum. The $\mathrm{pH}$ was maintained at 7.4 with a continuous $10-\mathrm{ml} / \mathrm{min}$ stream of filtered $10 \% \mathrm{CO}_{2}$ in air, confined by a chamber cap featuring a heated window to prevent condensation. A syringe infusion pump (Harvard Apparatus Pump 11, Holliston, MA) compensated for evaporation due to the dry airflow with sterile water injection of approximately $60 \mu \mathrm{l} / \mathrm{h}$. Neuronal electrical activity was recorded with a 64-channel amplifier system (Plexon Inc., Dallas, TX), and channels digitized simultaneously at $40 \mathrm{kHz}$. Total system gain was set to $1.1 \times 10^{4}$. Spike identification and separation was accomplished with a real time template-matching algorithm (Plexon Inc., Dallas, TX) to provide single-unit spike rate data. Electrodes/channels were assigned to 64 digital signal processors. Each processor could discriminate up to four different units (cellular components that generated detectable action potential waveforms for discrimination) in real time.

\subsection{Drugs and preparation of solutions}

All drugs were obtained from Sigma-Aldrich (St. Louis, MO) and prepared to concentrations that minimized osmolarity changes in the $2.0 \mathrm{ml}$ constant volume experimental bath. Retigabine, flupirtine, NS1619 and isopimaric acid were made to $10-100 \mathrm{mM}$ stock solution in dimethyl sulfoxide (DMSO) and applied at final concentrations of $1.0-50 \mu \mathrm{M}$. DMSO was kept below $0.5 \%(\mathrm{v} / \mathrm{v})$ in the experimental bath, a level at which no significant effects on neuronal activity or morphology were observed (Gopal et al., 2011). Pentylenetetrazol was made to a $200-\mu \mathrm{M}$ stock solution in double-distilled water.

\subsection{Data analyses}

Electrophysiologic activity was recorded as average spike rate and burst rate across each active unit (threshold of 10 spikes/min) in 1.0min bins. Bursts were derived from spike integration $(\tau=100 \mathrm{~ms})$ for each discriminated unit using a two-threshold method (see Morefield et al., 2000). Minute-mean data were normalized to the reference activity established by each respective network; this approach provided reproducible concentration-response curves obtained from the different networks (Gross, 2011). Extracellular action potential waveforms were sampled from a single unit at a rate of $40 \mathrm{kHz}$ and reconstructed from the average values of superimposed traces $(n=100)$. Amplitudes of the trough $\left(\mathrm{Na}^{+}\right.$component), late peak ( $\mathrm{K}^{+}$component), and the duration from trough to peak were measured. Average values were expressed as mean \pm S.E. M. Statistical analyses, linear and sigmoidal regressions were conducted using Prism software (Graphpad, La Jolla, CA). Significance was evaluated by analysis of variance (ANOVA) followed by Tukey's post-hoc test at $\alpha=0.05,0.01$, or 0.001 .

\section{Results}

\subsection{Auditory cortical network responses to $\mathrm{K}^{+}$channel openers}

Increasing concentrations $(1.0-50 \mu \mathrm{M})$ of each $\mathrm{K}^{+}$channel opener were applied sequentially to the medium bath (Fig. 1). Activity of the cells was measured as mean spike rate and mean burst rate of all active units (range: $30-100$ per array) in a network. The interval between each drug addition was approximately 15-30 min, allowing spike and burst activity to obtain a stable temporal plateau. Such plateau values were used for intranetwork normalization that allows a quantitative comparison of drug responses across different networks (Fig. 2A-D). Even at low concentrations (1.0-2.0 $\mu \mathrm{M})$, rapid inhibitory effects on network spike and burst rates were observed for all four drugs, although they often required up to $15 \mathrm{~min}$ of stabilization (e.g., see $2.0 \mu \mathrm{M}$ application in Fig. 1B). A decrease in spike and burst activity under retigabine and flupirtine at high concentrations $(>10 \mu \mathrm{M})$ was almost instantaneous (Fig. 1A-B). A different response dynamics was seen with NS1619 ( $>5 \mu \mathrm{M}$ ) - more gradual activity decreases lasting, in some cases, for more than 15 min (Fig. 1C). A transition from rapid to slow decreases in spike production was seen with isopameric acid between 10 and $20 \mu \mathrm{M}$ (half-life around $30 \mathrm{~min}$ ). 

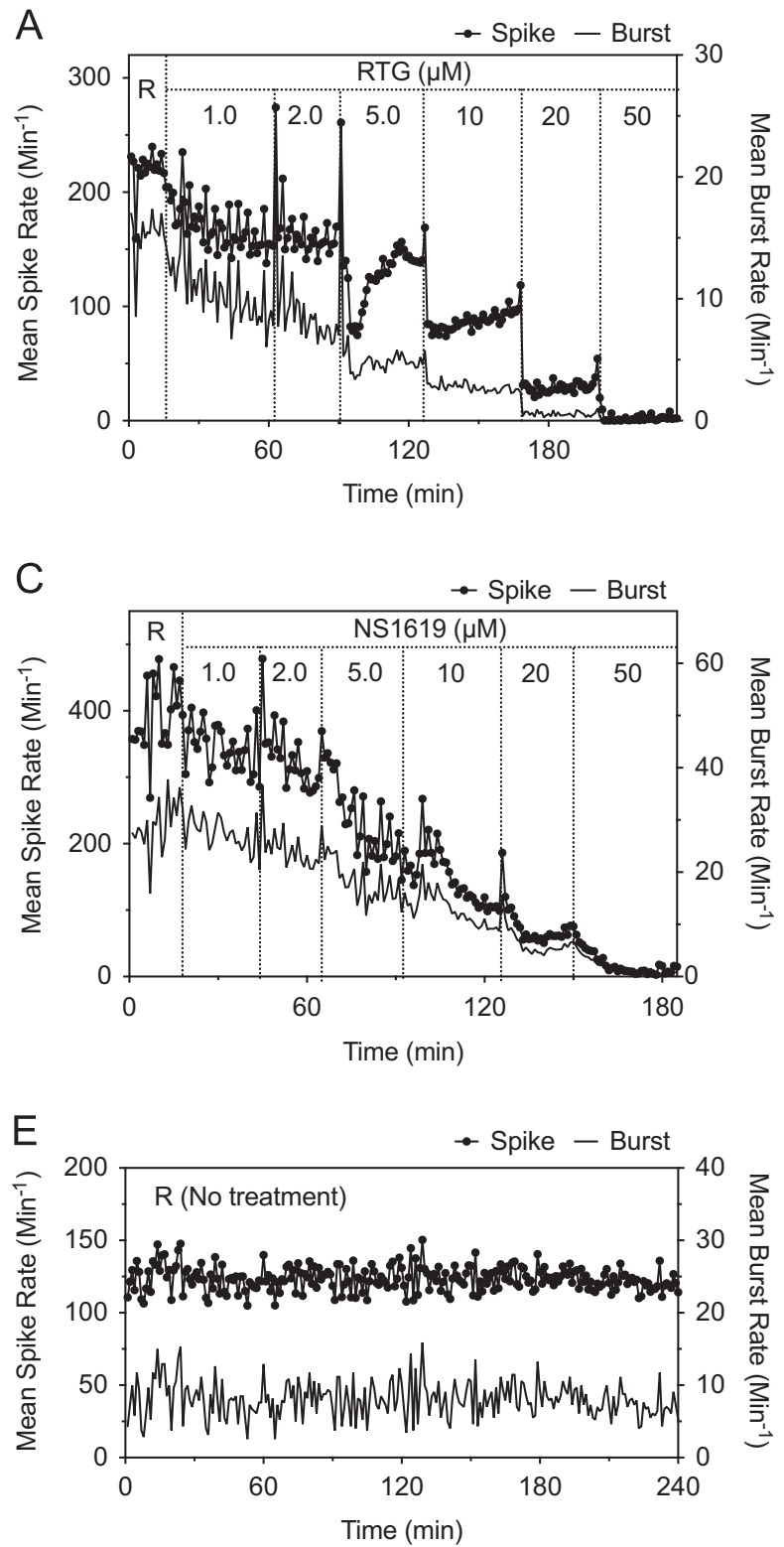
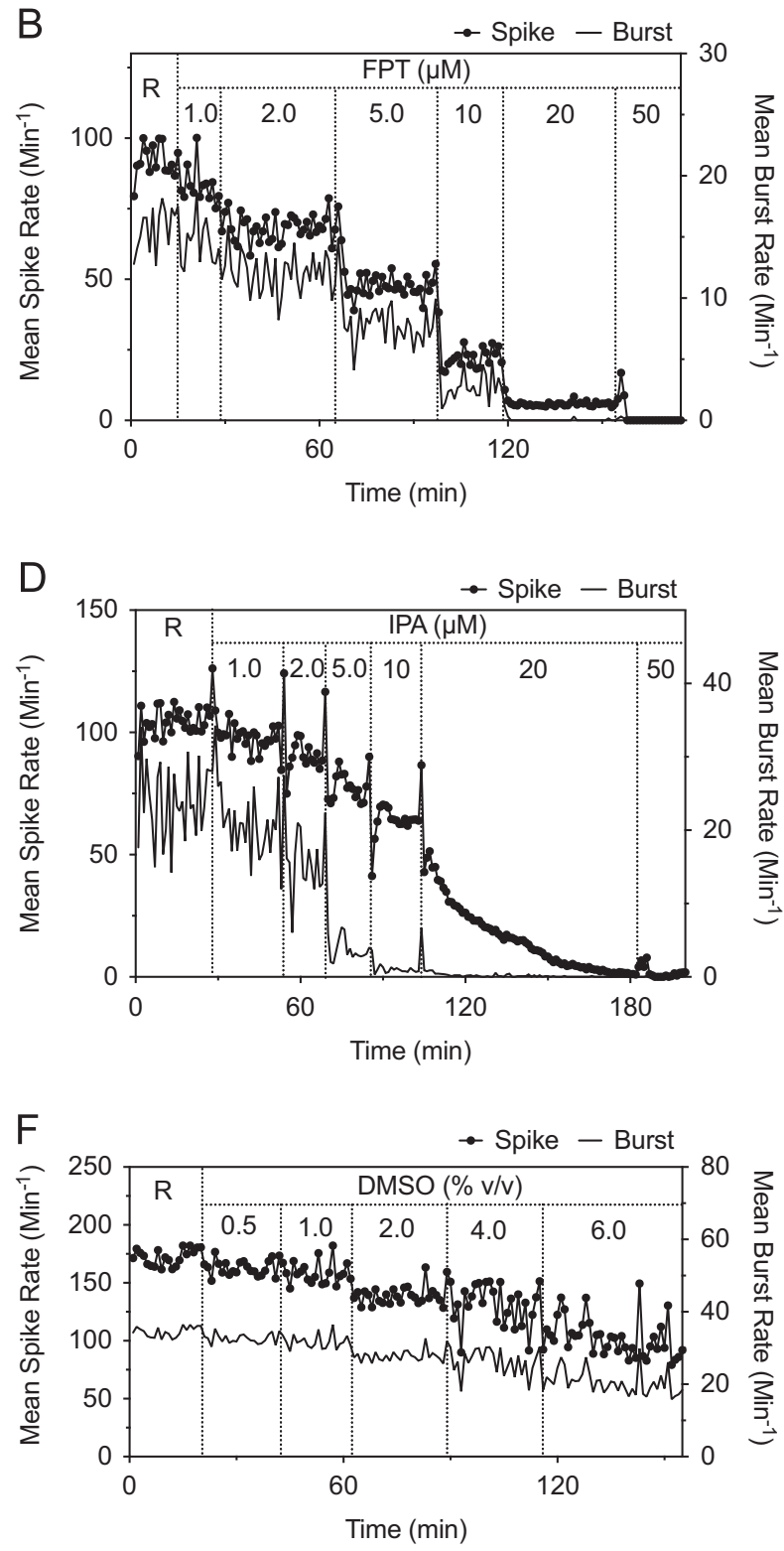

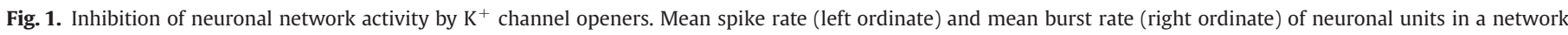

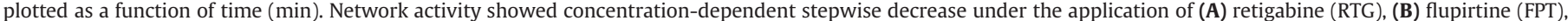

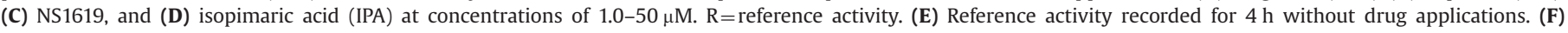
Concentration-response of vehicle (DMSO). Concentration of $0.5 \% \mathrm{v} / \mathrm{v}$ corresponds to the highest concentrations used in (A-D).

In this case the mean burst rate was more sensitive than the spike rate with responses immediately at the time of application (Fig. 1D). Fig. 1E showed the stability of spontaneous network activity under the native condition throughout the typical length of the experiment. Fig. $1 \mathrm{~F}$ shows the network response to the vehicle (DMSO). Note that at $0.5 \% \mathrm{v} / \mathrm{v}$, which corresponded to the highest concentration used in this study, there was no effect on network activity.

The four $\mathrm{K}^{+}$channel openers exerted full efficacy with complete inhibition of neuronal activity at $50 \mu \mathrm{M}$. Concentrationresponse curves were computed using a 4-parameter logistic fit of normalized spike rate from 0 to $100 \%$ (Fig. 2A-D). The $\mathrm{EC}_{50}$ of retigabine was $8.0 \mu \mathrm{M}(n=5$; Table 1$)$, with $\log \mathrm{EC}_{50}$ of $0.90 \pm 0.06$ (Fig. 2A, E). Flupirtine exhibited the highest potency $-\mathrm{EC}_{50}$ of $4.0 \mu \mathrm{M}\left(n=5 ; \log \mathrm{EC}_{50}=0.61 \pm 0.05\right)$ - followed by NS1619 with $\mathrm{EC}_{50}$ of $5.8 \mu \mathrm{M}\left(n=5 ; \log \mathrm{EC}_{50}=0.76 \pm 0.06\right)$, isopimaric acid with an $\mathrm{EC}_{50}$ of $7.8 \mu \mathrm{M}\left(n=3 ; \log \mathrm{EC}_{50}=0.89 \pm 0.05\right)$. Another parameter calculated by the sigmoidal regressions was the Hill coefficient
$\left(n_{\mathrm{H}}\right)$, which estimates the cooperativity of drug actions (Weiss, 1997). Among the $\mathrm{K}^{+}$channel opener drugs investigated, retigabine, flupirtine, and NS1619, exhibited comparable $n_{\mathrm{H}}$ values: $1.34 \pm 0.26$ (95\% CI: $[0.79,1.88]), 1.27 \pm 0.17 \quad[0.92,1.62]$, $1.39 \pm 0.24[0.89,1.89]$, respectively (Fig. $2 \mathrm{~F}$ ). These values are sufficiently close to 1.0 to imply a lack of cooperativity; however, isopimaric acid with an $n_{\mathrm{H}}$ of $1.9 \pm 0.3[1.10,2.78]$ suggests positive cooperativity between more than one binding site (Weiss, 1997).

The concentration-response relations were analyzed using the spike rate data, but the burst rate data seen in Fig. 1 were also considered. Normalized burst decreases - percent burst rate inhibition - were plotted against percent spike inhibition for each $\mathrm{K}^{+}$channel opener (Fig. 2G). All correlations were statistically significant $(P<0.0001)$. Modulatory effects of retigabine, flupirtine, and NS1619 on network burst rates were equivalent to their effects on spike rate, with linear-regression slopes overlapping at $1.1 \pm 0.1$ (Table 2), indicating one-to-one relations between spike inhibition and burst inhibition - i.e., 50\% burst inhibition at their 

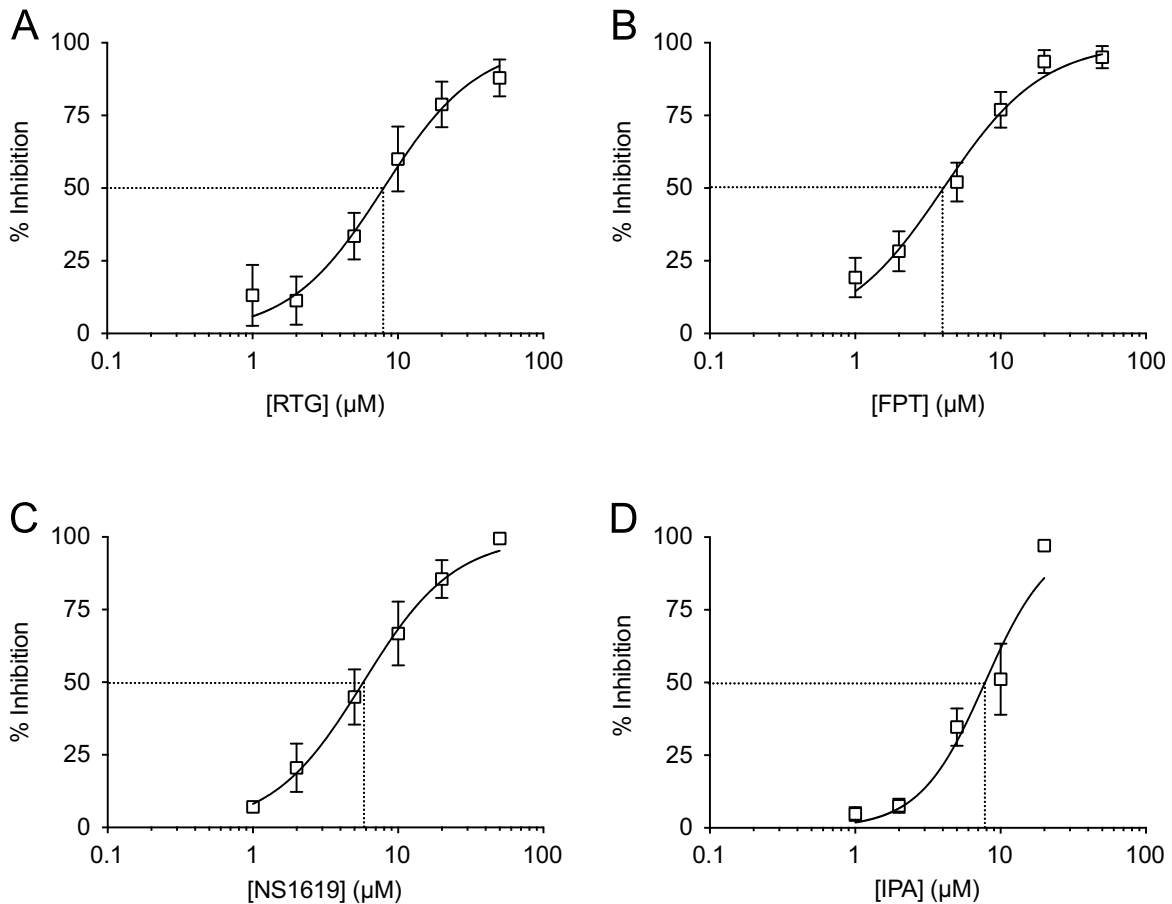
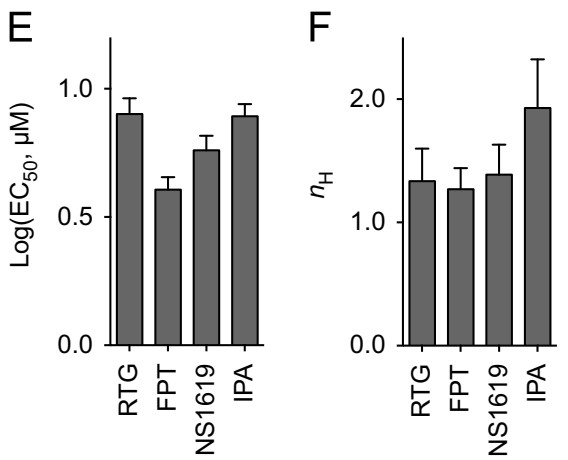

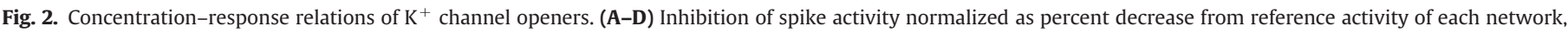

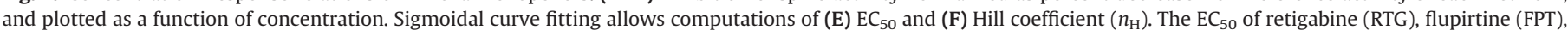

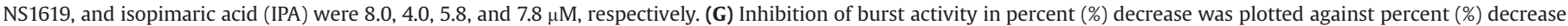

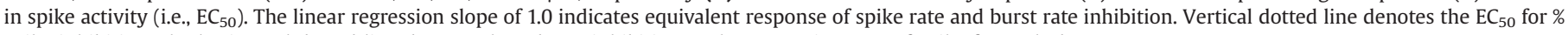
spike inhibition; the horizontal dotted line denotes the \% burst inhibition at the respective $\mathrm{EC}_{50}$ of spike for each drug.

Table 1

Comparison of $\mathrm{EC}_{50}$ and $\mathrm{TC}$ (therapeutic concentration) values of $\mathrm{K}+$ channel openers. 95\% Confidence intervals $(\mathrm{CI})$ were calculated by the curve fitting algorithm.

\begin{tabular}{lllcl}
\hline & $\mathrm{EC}_{50}(\mu \mathrm{M})$ & $95 \% \mathrm{CI}$ & $\mathrm{TC}(\mu \mathrm{M})$ & $95 \% \mathrm{CI}$ \\
\hline Retigabine & 8.0 & {$[5.6,10.2]$} & 7.4 & {$[5.9,9.2]$} \\
Flupirtine & 4.0 & {$[3.1,5.0]$} & 23.3 & {$[19.8,24.7]$} \\
NS1619 & 5.8 & {$[4.2,7.3]$} & 15.2 & {$[13.1,17.6]$} \\
Isopimaric acid & 7.8 & {$[6.0,9.7]$} & 30.1 & {$[21.0,42.9]$} \\
\hline
\end{tabular}

Table 2

Linear-regression analysis of correlation of spike-burst inhibition (Fig. 2G). Results of linear slopes are presented as mean \pm S.E.M, 95\% confidence intervals (CI), and correlation coefficient $\left(r^{2}\right)$.

\begin{tabular}{llll}
\hline & Slope & $95 \%$ CI & $r^{2}$ \\
\hline Retigabine & $1.08 \pm 0.08$ & {$[0.89,1.26]$} & 0.79 \\
Flupirtine & $1.15 \pm 0.06$ & {$[1.00,1.29]$} & 0.42 \\
NS1619 & $1.07 \pm 0.06$ & {$[0.94,1.20]$} & 0.83 \\
Isopimaric acid & $1.99 \pm 0.23$ & {$[1.47,2.50]$} & 0.71 \\
\hline
\end{tabular}

respective spike-inhibition $\mathrm{EC}_{50}$. Isopimaric acid, however, revealed a spike-burst correlation slope of 2.0 that is significantly different from other compounds, suggesting that the network bursts are inhibited at lower concentrations than spikes. This phenomenon was also observed in Fig. 1D for isopimaric acid as $90 \%$ of bursting was inhibited at a concentration that only reduced spike rate by $20 \%$. The $r^{2}$ value of flupirtine was lower - though correlation was statistically significant - compared to other compounds (Table 2). This may indicate perhaps a nonlinear relation between spike inhibition and burst inhibition for flupirtine.

Even though all four $\mathrm{K}^{+}$channel openers modulated spike activity with full efficacy at $50 \mu \mathrm{M}$, the full inhibitory effects at high concentrations could be linked to drug toxicity. Recovery of activity after medium changes is a good measure of such acute toxicity. The auditory cortex networks exposed to $50 \mu \mathrm{M}$ of each drug for $1.0 \mathrm{~h}$ were washed with a medium change at rate of approximately $0.1 \mathrm{ml} / \mathrm{s}$ for $1.0 \mathrm{~min}$. The stabilized activity levels (spike rate) recorded $1.0 \mathrm{~h}$ after the wash were quantified as percent of the reference activity before drug applications (Fig. 3A). Retigabine and flupirtine both exhibited full recoveries near $100 \%: 105.7 \pm 16.2 \%(n=5)$ and $102.7 \pm 19.3 \%(n=5)$, respectively (Fig. 3B). No overt morphological changes were observed (Fig. 3C and D). However, activity in networks exposed to $50 \mu \mathrm{M}$ NS1619 and isopimaric acid was not fully reversible: $66.3 \pm 11.4 \%$ $(n=5 ; P=0.04)$ and $6.5 \pm 3.7 \%(n=5 ; P=0.002)$. Networks also showed signs of morphological damage (Fig. $3 \mathrm{E}$ and $\mathrm{F}$ ) seen under phase contrast light microscopy as cell death, cell shrinkage, or loss of neural processes.

Since the $\mathrm{K}^{+}$channel openers induced network inhibition, the extent of their effect on action potential modulation were assessed and compared. Extracellular action potential waveforms were recorded under the untreated (native) or treated $(20 \mu \mathrm{M}$ of each $\mathrm{K}^{+}$channel openers) conditions for a 5-min period (Fig. 4A). The waveforms are proportional to the total membrane current (Gold et al., 2006). For irreversible metal electrodes, the amplitudes of the negative (inward) and positive (outward) peaks can be used to estimate the flux of $\mathrm{Na}^{+}$and $\mathrm{K}^{+}$ions, respectively. The duration of the action potential was measured from the occurrence of the negative peak to that of the positive peak, which marks the interval from the highest slope of depolarization to the highest slope of repolarization of an intracellular action potential. Waveforms can vary greatly among different units on different electrodes, but remain constant for each discriminated unit for periods of 12-24 h. This allowed normalization and comparison of the druginduced changes (amplitudes and duration; Fig. 4A). The amplitudes of the $\mathrm{Na}^{+}$components were unaffected by treatment using all drugs ( $n=9$ each; $P=0.9$; Fig. 4B). Retigabine and flupirtine 
A

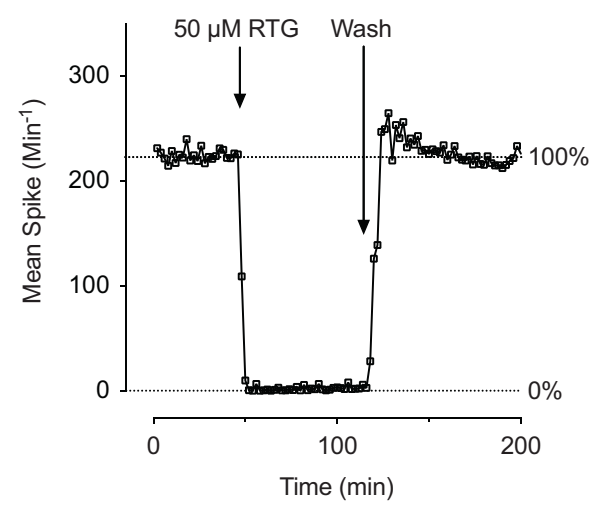

B
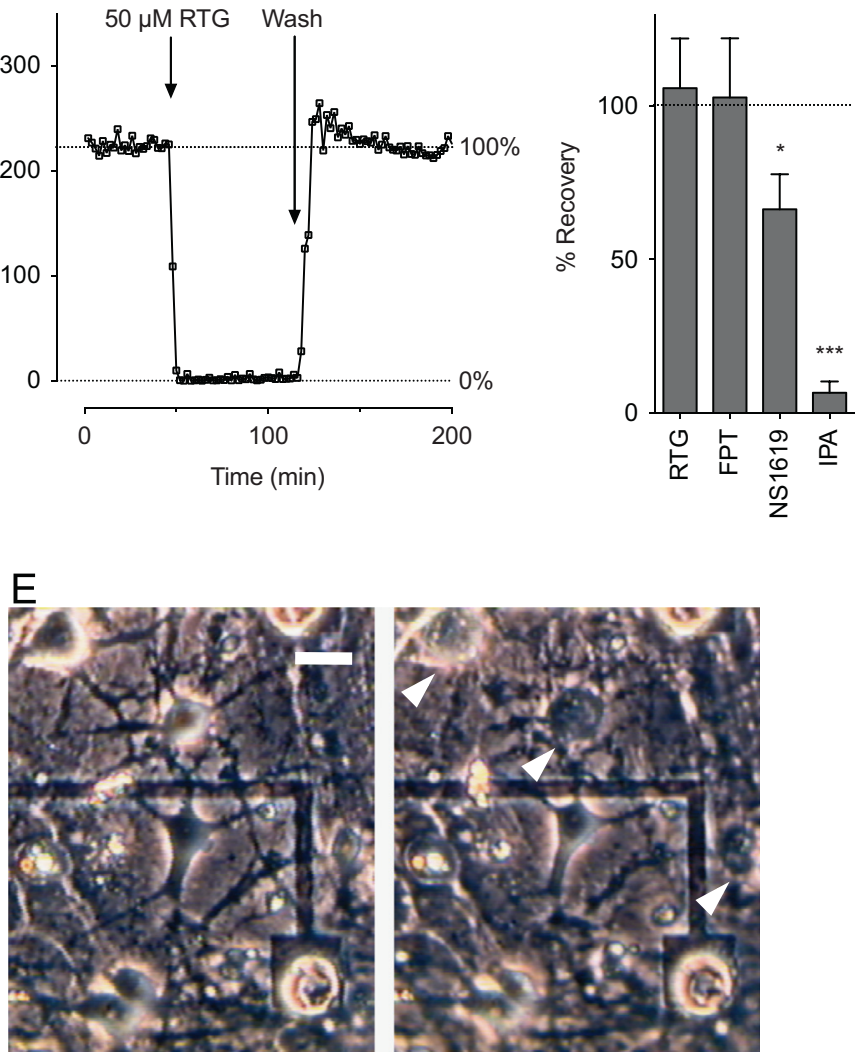

Native

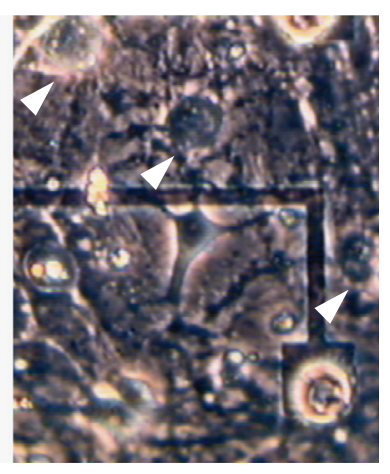

NS1619

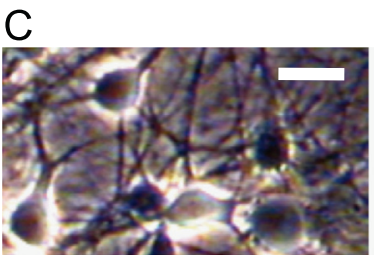

Native

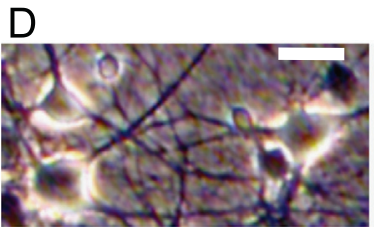

Native

$\mathrm{F}$

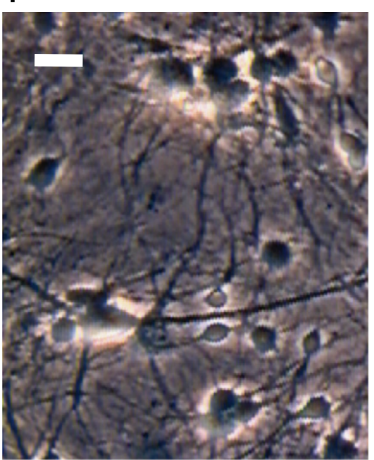

Native

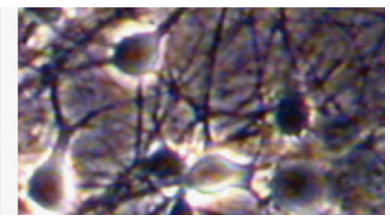

RTG

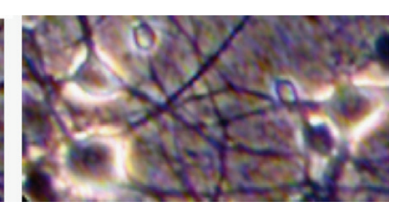

FPT

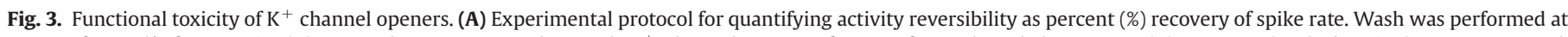

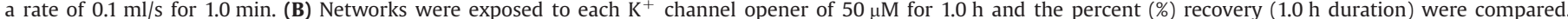

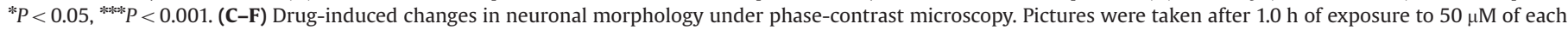
$\mathrm{K}^{+}$channel opener. Arrow marks the apparent cell deaths under NS1619 and IPA. Bar $=20 \mu \mathrm{m}(\mathbf{C}-\mathbf{F})$.

A

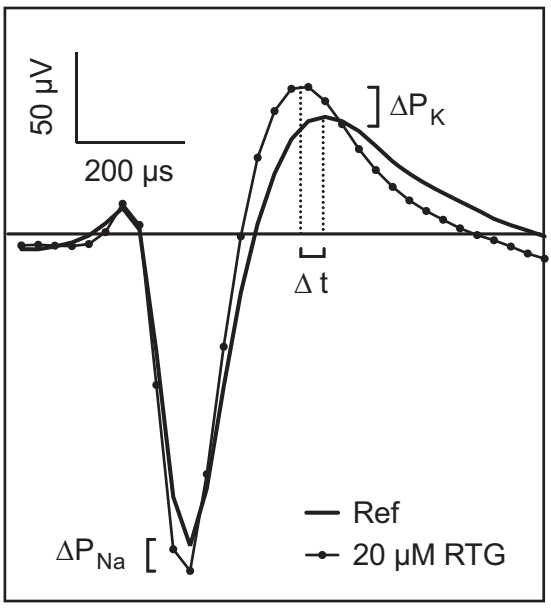

B

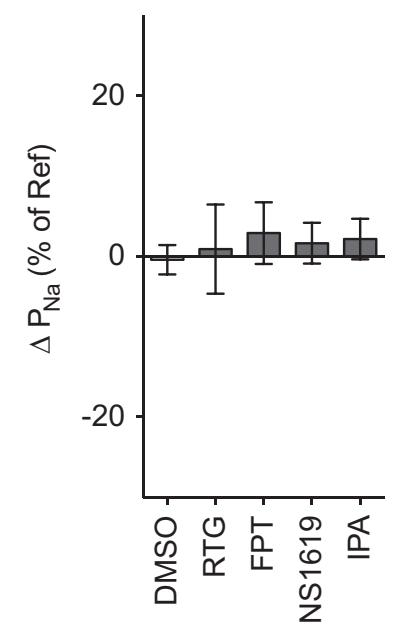

C

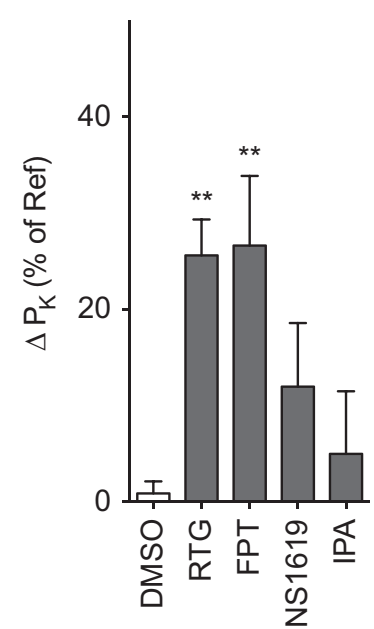

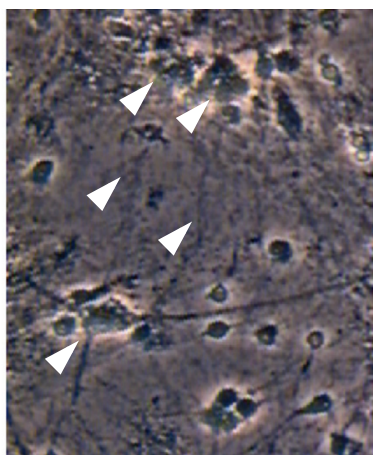

IPA

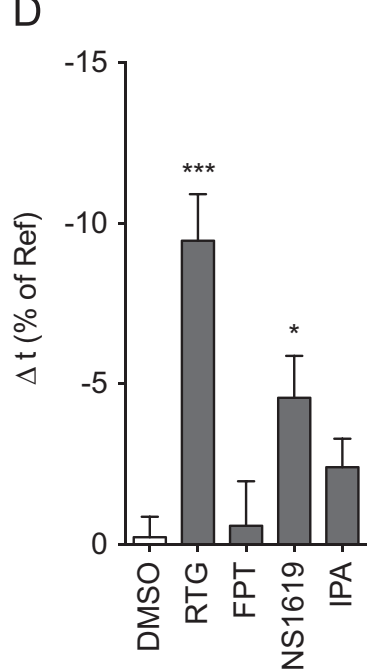

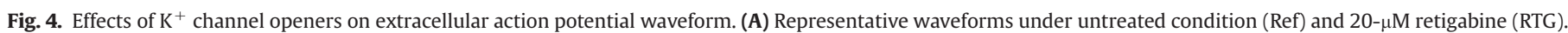

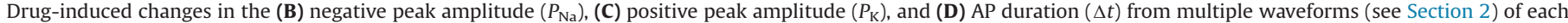

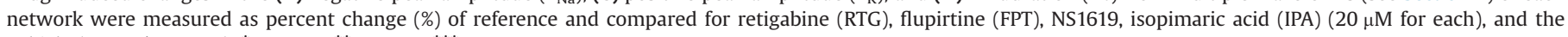
vehicle $\left(0.2 \% \mathrm{v} / \mathrm{v}\right.$ DMSO). ${ }^{*} P<0.05$, ${ }^{* *} P<0.01$, ${ }^{* * *} P<0.001$

increased the amplitude of the $\mathrm{K}^{+}$component by $25.6 \pm 3.7 \%$ $(P=0.004)$ and $26.6 \pm 7.2 \%(P=0.003)$, respectively (Fig. $4 C)$. The increases observed under NS1619 and isopimaric acid were not significant. However, modulations of action potential duration, as reflected in peak maxima positions, followed a different pattern.
Retigabine shortened the duration by $9.5 \pm 1.5 \%(P<0.0001)$, while flupirtine did not cause a change ( $P=1.0$; Fig. 4D). NS1619 did not significantly increase the $\mathrm{K}^{+}$amplitude, but did shorten the action potential duration by $4.6 \pm 1.3 \%(P=0.04)$. Isopimaric acid had no effect $(P=0.7)$. 
A

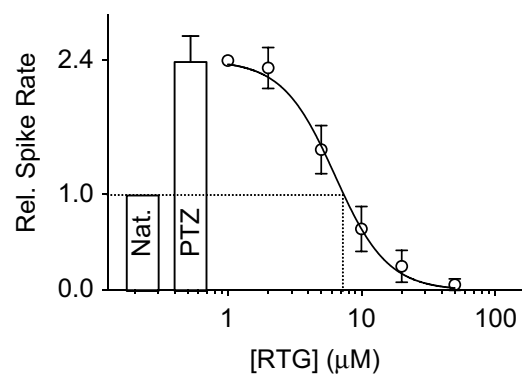

C

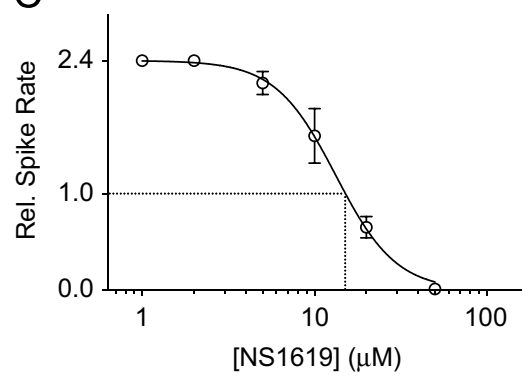

B

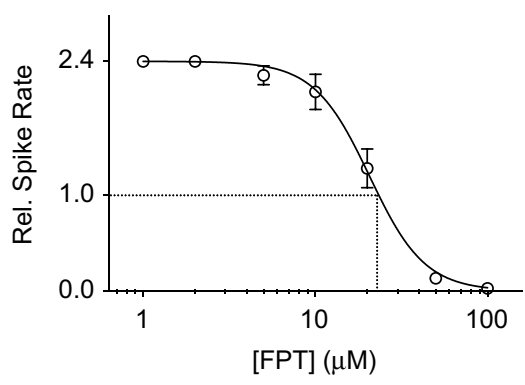

D

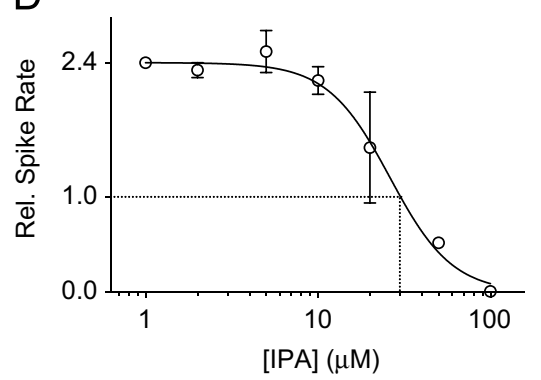

$\mathrm{E}$

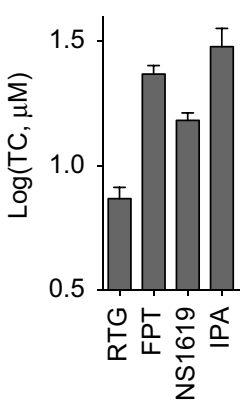

G

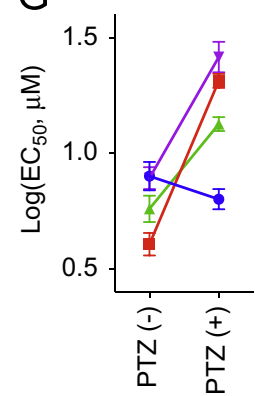

$\mathrm{F}$
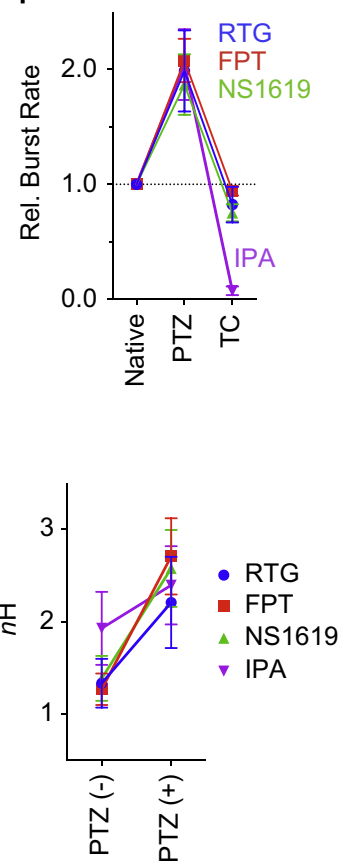

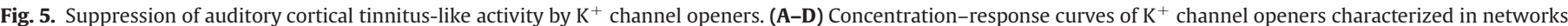

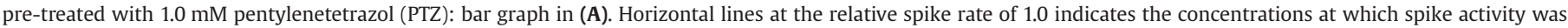

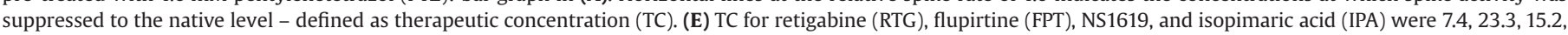

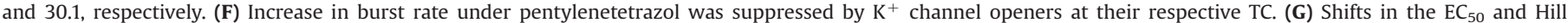
coefficient $\left(n_{\mathrm{H}}\right)$ values in the presence of $1.0 \mathrm{mM}$ pentylenetetrazol $(\mathrm{PTZ}(+))$, from the no-treatment $(\mathrm{PTZ}(-))$ condition shown in Fig. 2 .

\subsection{Suppression of pentylenetetrazol-induced cortical hyperactivity by $\mathrm{K}^{+}$channel openers}

In a previous study, we determined that pentylenetetrazol at $1.0 \mathrm{mM}$ induced a maximal activity increase in auditory cortical networks (Wu et al., 2011). This hyperactivity was used to characterize tinnitus-like activity (Viz., "a cell culture correlate of tinnitus") against which potential treatment drugs may be tested. Such tests would not only reveal the efficacy of a potential drug, but would also be able to quantify any associated toxicity. In the present study, pentylenetetrazol increased spike rate by $2.4 \pm 0.3$ fold ( $n=18$; Fig. $5 \mathrm{~A}$ bar), which agrees with our previous study $(P=0.9)$. The increase in burst rate was $1.9 \pm 0.2$ fold $(n=12$; Fig. $5 \mathrm{~F})$ - a number slightly lower than our previous data, but proved not to be statistically significant $(P=0.5)$. The concentration-response curves of each $\mathrm{K}^{+}$channel opener were calculated under activity induced by the $1.0 \mathrm{mM}$ pentylenetetrazol (Fig. 5A-D). The concentration at which hyperactivity was attenuated to the native level was considered the therapeutic concentration, at $\mathrm{EC}_{42}$ on the sigmoidal curve - calculated by the inverse of the relative increase under pentylenetetrazol. The calculated therapeutic concentrations (Table 1) for retigabine, flupirtine, NS1619, and isopimaric acid were $7.4 \mu \mathrm{M} \quad(n=5 ; \log \mathrm{TC}=0.87 \pm 0.05), 23.3 \mu \mathrm{M} \quad(n=5 ; \log \mathrm{TC}=$ $1.37 \pm 0.03), 15.2 \mu \mathrm{M}(n=3 ; \log \mathrm{TC}=1.18 \pm 0.03)$, and $30.1 \mu \mathrm{M}(n=3$; $\log \mathrm{TC}=1.48 \pm 0.07$ ), respectively (Fig. $5 \mathrm{E}$ ). The pentylenetetrazolinduced increase in burst rate was attenuated to a similar extent as that of spike rate (activity reduced to the native level) by retigabine, flupirtine, and NS1619 ( $n=3$ each) at their respective therapeutic concentrations (Fig. 5F). Isopimaric acid at the presumed therapeutic concentration of $30.1 \mu \mathrm{M}$ reduced the relative burst rate to $0(n=5$; Fig. 5F); the decaying phase shown in Fig. 1D at a concentration of $20 \mu \mathrm{M}$ was not observed until a level of $100 \mu \mathrm{M}$ was reached under the effects of pentylenetetrazol (data not shown).

Although showing effective suppression of hyperactivity, the concentration-response relations for all four $\mathrm{K}^{+}$channel openers under pentylenetetrazol were dissimilar to that under the native condition. For flupirtine, the most potent among the $\mathrm{K}^{+}$channel openers in the native condition, the $\log \mathrm{EC}_{50}$ value increased 2-fold under pentylenetetrazol to $1.31 \pm 0.03$ ( $n=5$; Fig. $5 \mathrm{G}$ - left panel), or a near 5-fold increase in the $\mathrm{EC}_{50}(4.0-21 \mu \mathrm{M})$. NS1619 and isopimaric acid also exhibited higher $\log \mathrm{EC}_{50}$ values under pentylenetetrazol: near a 1.5-fold increase to $1.13 \pm 0.03(n=3)$ and $1.42 \pm 0.07(n=3)$, respectively. The only exception was retigabine; the presence of pentylenetetrazol shifted the $\mathrm{EC}_{50}$ of in a different direction to a lower value of $0.80 \pm 0.04(n=5)$. NS1619, with a lower degree of a potency shift, was the second most potent after retigabine, followed by flupirtine and isopimaric acid (Fig. 5E). In addition, the presence of pentylenetetrazol also shifted the slope $\left(n_{\mathrm{H}}\right)$ - increased the cooperativity - of retigabine, flupirtine, $\mathrm{NS} 1619$, and isopimaric acid to $2.2 \pm 0.5,2.7 \pm 0.4,2.6 \pm 0.4$, and $2.5 \pm 0.4$, respectively (Fig. $5 G$ - right panel).

\section{Discussion}

\subsection{Drug screening via measurements of multi-unit responses}

We quantified the pharmacological profiles of four $\mathrm{K}^{+}$channel openers - retigabine, flupirtine, NS1619, and isopimaric acid, using multi-site measurements of neuronal network responses with microelectrode arrays. The dissociated auditory cortical cells grown in vitro form and retain all the characteristic of a functional network - spontaneous activity supported by various neuronal and non-neuronal cell types, and stereotypic response to pharmacological manipulation in the form of excitation/inhibition - that resemble closely the activity patterns of the parent tissue (Johnstone et al., 2010). This platform not only provides rapid drug-screening capabilities but also may reveal relevant information on tissue-specific drug response at the network level.

For retigabine, the $\mathrm{EC}_{50}(8.0 \mu \mathrm{M})$ determined in this study was comparable, though slightly higher, than the $\mathrm{EC}_{50}$ for $\mathrm{K}_{\mathrm{V}} 7$ subtype 
current activation (0.6-6.2 $\mu \mathrm{M} ; n_{\mathrm{H}} \sim 1.0$ for each subtype; Tatulian et al., 2001). Retigabine at this concentration range induced observable network inhibitory effects (Fig. 1A; 2A). The inhibitory effects on neuronal spike and burst properties were shown in hippocampal slice at similar concentrations (1.0-10 $\mu \mathrm{M}$; Yue and Yaari, 2004). Several studies using an in vitro drug-induced model of epilepsy determined the effective range of retigabine against seizure-like events to be around $10-50 \mu \mathrm{M}$ (low magnesium-induced model; Armand et al., 2000) or 1.0-10 $\mu \mathrm{M}$ (kainate-induced model; Smith et al., 2007). At concentrations around 10-fold of that acting on the $\mathrm{K}_{\mathrm{V}} 7$ channels, retigabine was implicated in potentiating GABAergic transmission (Gunthorpe et al., 2012). In a study done by Otto et al. (2002) using cultured cortical neurons, it was found that retigabine at concentrations of $10-50 \mu \mathrm{M}$ increased GABAergic transmission via direct postsynaptic actions. Our results showed that this effect was not apparent at the network level, and perhaps not the major cause of network inhibition, as the presence of $\mathrm{GABA}_{\mathrm{A}}$ blocker pentylenetetrazol did not significantly affect the inhibitory potency of retigabine (Fig. 5G). Multiple single-unit recordings confirmed that retigabine altered the $\mathrm{K}^{+}$component of action potentials as its supposed mechanism (Fig. 4).

\subsection{Comparison of pharmacological responses within and between drug classes}

Flupirtine, a congener compound of retigabine, was developed before the $\mathrm{K}_{\mathrm{V}} 7$ channels were recognized as therapeutic targets, and consequently categorized as a non-opioid and non-NSAID analgesic with an unknown mechanism of action (Devulder, 2010). Recent discoveries of flupirtine as an activator of the $\mathrm{K}_{\mathrm{V}} 7$ channels - at comparable concentrations as retigabine $(2-6 \mu \mathrm{M}$; Kornhuber et al. 1999; Miceli et al., 2008) - caused the rethinking of its therapeutic potential. Although retigabine superseded flupirtine in an early stage of antiepileptic drug development as a better derivative with higher efficacy (Rostock et al., 1996), the two drugs were not drastically different in many respects. Retigabine had shown an antinociceptive effect similar to that of flupirtine (Blackburn-Munro et al., 2003). The neuroprotective actions of both drugs were indistinguishable against toxicity of L-glutamate, NMDA, oxygen, or glucose deprivation (Boscia et al., 2006; Seyfried et al., 2000). In this study, we found that flupirtine was twice as potent in its inhibitory effect on the auditory cortical networks as retigabine $(4 \mu \mathrm{M}$ vs. $8 \mu \mathrm{M})$, and exerted significantly different effects on extracellular action potentials. This is perhaps due to other mechanisms of flupirtine at comparable concentrations, such as the effect on the G-protein coupled inwardly rectifying $\mathrm{K}^{+}$current at the $\mathrm{EC}_{50}$ of $0.6 \mu \mathrm{M}$ (Jakob and Krieglstein, 1997), or the potentiation of $\mathrm{GABA}_{\mathrm{A}}$ current at $<10 \mu \mathrm{M}$ (Klinger et al., 2012). Expectedly, we observed a significant GABAergic effect of flupirtine, as the $\mathrm{EC}_{50}$ increased 6-fold under the presence of the $\mathrm{GABA}_{\mathrm{A}}$ blocker pentylenetetrazol, an effect of which was not apparent for retigabine.

The BK channel opener NS1619 and isopimaric acid both exhibited concentration-dependent inhibitory effect with full efficacy. Isopimaric acid exhibited an $\mathrm{EC}_{50}$ of $7.8 \mu \mathrm{M}$, near the concentrations at which BK channel activation was observed (10 $\mu \mathrm{M}$; Imaizumi et al., 2002). However, the $\mathrm{EC}_{50}$ of $5.8 \mu \mathrm{M}$ for NS1619 was lower than the reported concentration for BK channel activation in cortical neurons at $30 \mu \mathrm{M}$ (EC 50 ; Lee et al., 1995), as well as that for spike activity modulation at $10 \mu \mathrm{M}$ (Zhang et al., 2003). We speculate that the low $\mathrm{EC}_{50}$ of NS1619 in this study may perhaps be explained by its possible GABAergic mechanism. Although no study has shown a link between NS1619 and GABA neurotransmission, other derivatives of benzimidazole were developed as $\mathrm{GABA}_{A}$ ligands (Jain et al., 2010). In this study, we observed a significant potency shift of NS1619 under pentylenetetrazol, in a manner similar to flupirtine. Isopimaric acid also exhibited a GABAergic effect, although observed at a much lower
$\mathrm{EC}_{50}$ than that reported in the literature (around $300 \mu \mathrm{M}$; Zaugg et al., 2011). Unlike NS1619, isopimaric acid did not reduce the action potential duration, which is a consequence of BK channel activation (Scholz et al., 1998), and completely abolished network burst rate at concentrations lower than the $\mathrm{EC}_{50}$ of spike production. Possible explanation of this phenomenon may be that the opening of the BK channel by isopimaric acid affects preferentially the calcium-activated process, and thereby, changes the calcium-dependent synaptic regulation, as well as burst regulation (Kudela et al., 2009), while NS1619 modulates the voltage-gated properties of the BK channel, showing pharmacological profiles more closely resembling the $\mathrm{K}_{\mathrm{V}} 7$ openers. It must be noted that at the concentrations of complete activity inhibition $(50 \mu \mathrm{M})$, effects of retigabine and flupirtine were fully reversible, whereas that of NS1619 and isopimaric acid were partially reversible based upon recovery of activity. In Chinese hamster ovary cells, isopimaric acid extracted from natural compounds exhibited a $\mathrm{LD}_{50}$ equivalent to $54 \mu \mathrm{M}$ (Anaya et al., 2003), and NS1619 was reported to be toxic to glial cells at $100 \mu \mathrm{M}$ (Rundén-Pran et al. 2002). Both of these observations were corroborated by our data.

\subsection{Clinical relevance of $\mathrm{K}^{+}$channel openers on the pentylenetetrazol model of tinnitus}

Tinnitus describes the subjective experience of an auditory phantom sound; decades of studies have established a number of putative neural correlate for this subjective pathological phenomenon - among one, namely, the increase of the spontaneous firing rate and spatial coordination in the auditory cortex (Roberts et al., 2010). As an emergent property of aberrant cortical activity, tinnitus, thus, is ideally characterized by studying neuronal networks. Electrophysiological measurement of auditory cortical activity using the microelectrode array is a suitable platform in an attempt to elucidate this phenomenon. In our previous study, we used the pro-convulsant pentylenetetrazol to induce tinnituslike activity (or a cell culture correlate of tinnitus; Wu et al., 2011). The use of pentylenetetrazol for mimicking tinnitus was a novel approach and unprecedented. Firstly, other conventional tinnitus inducers such as salicylate or quinine had a postulated convergent mechanism that either directly or indirectly targeted the GABAergic inhibitory interneuron of the afferent pathway in the auditory cortex, resulting in disrupted plasticity of excitation-inhibition and resulting hyperactivity (Noreña et al., 2010). In addition, it should be noted that age-related tinnitus co-exhibited decreased inhibitory neurotransmission in the auditory cortex and along the auditory subcortical pathway (Caspary et al., 2013; Richardson et al., 2012). We used a simplified cortical disinhibition model with the $\mathrm{GABA}_{\mathrm{A}}$ antagonist pentylenetetrazol. The pentylenetetrazol model of epilepsy - pathology of which also stemmed from perhaps maladaptive plasticity and hyperactivity (Scharfman, 2002) - has been well-established in the literature, and this helps to facilitate the application, screening of, and re-purposing of antiepileptic drugs for tinnitus management.

Li et al. (2013) demonstrated the role of the $\mathrm{K}_{\mathrm{V}} 7$ channels in the induction of tinnitus in the mouse dorsal cochlear nucleus model, and showed that retigabine may prevent the development of tinnitus. We estimated the therapeutic potential of $\mathrm{K}^{+}$channel openers in suppressing tinnitus-like activity by quantifying the responses in the auditory cortical networks. Retigabine had the highest therapeutic potential, with a therapeutic concentration of $7.4 \mu \mathrm{M}$ - a concentration at which counteraction against inducedhyperactivity were effective - followed by NS1619 $(15.2 \mu \mathrm{M})$, flupirtine $(23.3 \mu \mathrm{M})$, and isopimaric acid $(30.0 \mu \mathrm{M})$. These values were well within the range of their effective concentrations against epilepsy (3-100 $\mu \mathrm{M}$; Kobayashi et al., 2008), thus, possible off-label treatment for tinnitus is plausible (and safe). Clinical studies had calculated the free brain concentration of retigabine taken at $1200 \mathrm{mg} /$ day to be 
around $2.0 \mu \mathrm{M}$ (Large et al., 2012) - a dose equivalent to that used in an animal model of pentylenetetrazol-induced seizure (Rostock et al., 1996). The other three compounds have not undergone pharmacokinetic studies. However, as their $\mathrm{EC}_{50}$ and therapeutic concentration values are almost comparable to retigabine, it is reasonable to assume that the potential effect of tinnitus-like activity suppression may be observed at a similar dose. Nevertheless, a controlled clinical trial of these other three drugs is warranted. As interest in this new class of drugs have gained traction, we surmise that the results of this study may serve as the basis for future research that might explore the pre-clinical and clinical effectiveness of $\mathrm{K}^{+}$channel openers for the treatment of tinnitus.

\section{Acknowledgments}

This research was supported in part by a Faculty Research Grant from UNT (EJM, 62313), by the Once Upon a Time Foundation (EJM, 64301), and by the Charles Bowen Memorial Endowment to the Center for Network Neuroscience (GG, \#178). We are thankful for the expert support from Ahmet Ors for microelectrode array manufacturing, and the assistance in cell culture from Nicole Calderon and Christina Nguyen.

\section{References}

Anaya, A.L., Mata, R., Sims, J.J., González-Coloma, A., Cruz-Ortega, R., Guadaño, A. Hernández-Bautista, B.E., Midland, S.L., Ríos, R., Gómez-Pompa, A., 2003. Allelochemical potential of Callicarpa acuminata. J. Chem. Ecol. 29, 2761-2776.

Armand, V., Rundfeldt, C., Heinemann, U., 2000. Effects of retigabine (D-23129) on different patterns of epileptiform activity induced by low magnesium in rat entorhinal cortex hippocampal slices. Epilepsia 41, 28-33.

Blackburn-Munro, G. Jensen, B.S., 2003. The anticonvulsant retigabine attenuates nociceptive behaviours in rat models of persistent and neuropathic pain. Eur. J. Pharmacol. 460, 109-116.

Boscia, F., Annunziato, L., Taglialatela, M., 2006. Retigabine and flupirtine exert neuroprotective actions in organotypic hippocampal cultures. Neuropharmacology 51, 283-294.

Caspary, D.M., Hughes, L.F., Ling, L.L., 2013. Age-related GABAA receptor changes in rat auditory cortex. Neurobiol. Aging 34, 1486-1496.

Chen, S.R., Cai, Y.Q., Pan, H.L., 2009. Plasticity and emerging role of BKCa channels in nociceptive control in neuropathic pain. J. Neurochem. 110, 352-362.

Devulder, J., 2010. Flupirtine in pain management: pharmacological properties and clinical use. CNS Drugs 24, 867-881.

Eggermont, J.J., 2008. Role of auditory cortex in noise- and drug-induced tinnitus. Am. J. Audiol. 17, S162-S169.

Gold, C., Henze, D.A., Koch, C., Buzsáki, G., 2006. On the origin of the extracellular action potential waveform: Aa modeling study. J. Neurophysiol. 95, 3113-3128.

Gopal, K.V., Gross, G.W., 1996. Auditory cortical neurons in vitro: initial pharmacological studies. Acta Otolaryngol. 116, 697-704.

Gopal, K.V., Wu, C., Moore, E.J., Gross, G.W., 2011. Assessment of styrene oxide neurotoxicity using in vitro auditory cortex networks. ISRN Otolaryngol. 2011, 204804.

Gross, G.W. 2011. Multielectrode arrays. Scholarpedia 6, 5749.

Gross, G.W., Wen, W., Lin, J., 1985. Transparent indium-tin oxide patterns for extracellular multisite recording in neuronal cultures. J. Neurosci. Methods 15 , $243-252$

Gunthorpe, M.J., Large, C.H., Sankar, R., 2012. The mechanism of action of retigabine (ezogabine) a first-in-class $\mathrm{K}+$ channel opener for the treatment of epilepsy. Epilepsia 53, 412-424.

Imaizumi, Y., Sakamoto, K., Yamada, A., Hotta, A., Ohya, S., Muraki, K., Uchiyama, M., Ohwada, T., 2002. Molecular basis of pimarane compounds as novel activators of large-conductance $\mathrm{Ca}(2+)$-activated $\mathrm{K}(+)$ channel alpha-subunit. Mol. Pharmacol. 62, 836-846.

Jaffe, D.B., Wang, B., Brenner, R., 2011. Shaping of action potentials by type I and type II large-conductance Ca2 +-activated K+ channels. Neuroscience 192, 205-218.

Jain, P., Sharma, P.K., Rajak, H., Pawar, R.S., Patil, U.K., Singour, P.K., 2010. Design synthesis and biological evaluation of some novel benzimidazole derivatives for their potential anticonvulsant activity. Arch. Pharm. Res. 33, 971-980.

Jakob, R., Krieglstein, J., 1997. Influence of flupirtine on a G-protein coupled inwardly rectifying potassium current in hippocampal neurones. Br. J. Pharmacol. 122, 1333-1338.

Johnstone, A.F., Gross, G.W., Weiss, D.G., Schroeder, O.H., Gramowski, A., Shafer, T.J., 2010. Microelectrode arrays: a physiologically based neurotoxicity testing platform for the 21st century. Neurotoxicology 31, 331-350.

Jentsch, T.J., 2000. Neuronal KCNQ potassium channels: physiology and role in disease. Nat. Rev. Neurosci. 1, 21-30.
Kaltenbach, J.A., 2007. The dorsal cochlear nucleus as a contributor to tinnitus: mechanisms underlying the induction of hyperactivity. Prog. Brain Res. 166, 89-106.

Klinger, F., Geier, P., Dorostkar, M.M., Chandaka, G.K., Yousuf, A., Salzer, I., Kubista, H., Boehm, S., 2012. Concomitant facilitation of GABAA receptors and KV7 channels by the non-opioid analgesic flupirtine. Br. J. Pharmacol. 166, 1631-1642.

Kobayashi, K., Nishizawa, Y., Sawada, K., Ogura, H., Miyabe, M., 2008. K+-channel openers suppress epileptiform activities induced by 4-aminopyridine in cultured rat hippocampal neurons. J. Pharm. Sci. 108, 517-528.

Kornhuber, J., Maler, M., Wiltfang, J., Bleich, S., Degner, D., Rüther, E., 1999. Neuronal potassium channel opening with flupirtine. Fortschr. Neurol. Psychiatr. 67, 466-475.

Kudela, P., Bergey, G.K., Franaszczuk, P.J., 2009. Calcium involvement in regulation of neuronal bursting in disinhibited neuronal networks: insights from calcium studies in a spherical cell model. Biophys. J. 97, 3065-3074.

Large, C.H., Sokal, D.M., Nehlig, A., Gunthorpe, M.J., Sankar, R., Crean, C.S. Vanlandingham, K.E., White, H.S., 2012. The spectrum of anticonvulsant efficacy of retigabine (ezogabine) in animal models: implications for clinical use. Epilepsia 53, 425-436.

Lee, K., Rowe, I., Ashford, M., 1995. NS1619 activates BK Ca channel activity in rat cortical neurones. Eur. J. Pharmacol. 280, 215-219.

Li, S., Choi, V., Tzounopoulos, T., 2013. Pathogenic plasticity of Kv7.2/3 channel activity is essential for the induction of tinnitus. Proc. Natl. Acad. Sci. USA 110, 9980-9985.

Manzoor, N.F., Licari, F.G., Klapchar, M., Elkin, R.L., Gao, Y., Chen, G., Kaltenbach, J.A., 2012. Noise-induced hyperactivity in the inferior colliculus: its relationship with hyperactivity in the dorsal cochlear nucleus. J. Neurophysiol. 108, 976-988.

Morefield, S.I., Keefer, E.W., Chapman, K.D., Gross, G.W., 2000. Drug evaluations using neuronal networks cultured on microelectrode arrays. Biosens. Bioelectron. 15, 383-396.

Miceli, F., Soldovieri, M.V., Martire, M., Taglialatela, M., 2008. Molecular pharmacology and therapeutic potential of neuronal Kv7-modulating drugs. Curr. Opin. Pharmacol. 8, 65-74.

N'Gouemo, P., 2011. Targeting BK (big potassium) channels in epilepsy. Expert Opin. Ther. Targets 15, 1283-1295.

Nodera, H., Spieker, A., Sung, M., Rutkove, S., 2011. Neuroprotective effects of Kv7 channel agonist retigabine for cisplatin-induced peripheral neuropathy. Neurosci. Lett. 505, 223-227.

Noreña, A.J., Moffat, G., Blanc, J.L., Pezard, L., Cazals, Y., 2010. Neural changes in the auditory cortex of awake guinea pigs after two tinnitus inducers: salicylate and acoustic trauma. Neuroscience 166, 1194-1209.

Otto, J.F., Kimball, M.M., Wilcox, K.S., 2002. Effects of the anticonvulsant retigabine on cultured cortical neurons: changes in electroresponsive properties and synaptic transmission. Mol. Pharmacol. 61, 921-927.

Richardson, B.D., Brozoski, T.J., Ling, L.L., Caspary, D.M., 2012. Targeting inhibitory neurotransmission in tinnitus. Brain Res. 1485, 77-87.

Roberts, L.E., Eggermont, J.J., Caspary, D.M., Shore, S.E., Melcher, J.R., Kaltenbach, J.A., 2010. Ringing ears: the neuroscience of tinnitus. J. Neurosci. 30, 14972-14979.

Rostock, A., Tober, C., Rundfeldt, C., Bartsch, R., Engel, J., Polymeropoulos, E., Kutscher, B., Löscher, W., Hönack, D., White, H.S., Wolf, H.H., 1996. D-23129: a new anticonvulsant with a broad spectrum activity in animal models of epileptic seizures. Epilepsy Res. 23, 211-223.

Rundén-Pran, E., Haug, F.M., Storm, J.F., Ottersen, O.P., 2002. BK channel activity determines the extent of cell degeneration after oxygen and glucose deprivation: a study in organotypical hippocampal slice cultures. Neuroscience 112, 277-288.

Scharfman, H.E., 2002. Epilepsy as an example of neural plasticity. Neuroscientist 8, $154-173$.

Scholz, A., Gruss, M., Vogel, W., 1998. Properties and functions of calcium-activated $\mathrm{K}+$ channels in small neurones of rat dorsal root ganglion studied in a thin slice preparation. J. Physiol. 513, 55-69.

Seyfried, J., Evert, B.O., Rundfeldt, C., Schulz, J.B., Kovar, K.A., Klockgether, T., Wüllner, U., 2000. Flupirtine and retigabine prevent L-glutamate toxicity in rat pheochromocytoma PC 12 cells. Eur. J. Pharmacol. 400, 155-166.

Smith, M.D., Adams, A.C., Saunders, G.W., White, H.S., Wilcox, K.S., 2007. Phenytoinand carbamazepine-resistant spontaneous bursting in rat entorhinal cortex is blocked by retigabine in vitro. Epilepsy Res. 74, 97-106.

Tatulian, L., Delmas, P., Abogadie, F.C., Brown, D.A., 2001. Activation of expressed KCNQ potassium currents and native neuronal M-type potassium currents by the anti-convulsant drug retigabine. J. Neurosci. 21, 5535-5545.

Weiss, J.N., 1997. The Hill equation revisited: uses and misuses. FASEB J. 11, $835-841$.

Wu, C., Gopal, K.V., Gross, G.W., Lukas, T.J., Moore, E.J., 2011. An in vitro model for testing drugs to treat tinnitus. Eur. J. Pharmacol. 667, 188-194.

Wulff, H., Castle, N., Pardo, L., 2009. Voltage-gated potassium channels as therapeutic drug targets. Nat. Rev. Drug Discov. 8, 982-1001.

Yue, C., Yaari, Y., 2004. KCNQ/M channels control spike afterdepolarization and burst generation in hippocampal neurons. J. Neurosci. 24, 4614-4624.

Zaugg, J., Khom, S., Eigenmann, D., Baburin, I., Hamburger, M., Hering, S., 2011. Identification and characterization of GABA(A) receptor modulatory diterpenes from Biota orientalis that decrease locomotor activity in mice. J. Nat. Prod. 74, 1764-1772.

Zhang, X.F., Gopalakrishnan, M., Shieh, C.C., 2003. Modulation of action potential firing by iberiotoxin and NS1619 in rat dorsal root ganglion neurons. Neuroscience 122, 1003-1011. 